\title{
Effect of social factors on winter hospital admission for respiratory disease: a case-control study of older people in the UK
}

Rachel E Jordan, Jeremy I Hawker, Jon G Ayres, Peymané Adab, William Tunnicliffe, Babatunde Olowokure, Joe Kai, Richard J McManus, Ros Salter and Kar Keung Cheng

\begin{abstract}
\section{Background}

Every winter, hospitals in the UK and other developed countries experience a surge in respiratory admissions. Ecological studies suggest that social circumstances may be an important determinant.
\end{abstract}

Aim

To establish the most important factors associated with winter hospital admissions among older people presenting with acute respiratory disease, especially the relative effect of social factors.

Design of study

case-control study.

Setting

Seventy-nine general practices in central England.

Method

Of a cohort of patients consulting medical services with lower respiratory tract infection or exacerbation of chronic respiratory disease, 157 hospitalised cases were compared to 639 controls. Social, medical, and other factors were examined by interview and GP records.

\section{Results}

Measures of material deprivation were not significant risk factors for admission at either individual or area level, although social isolation (odds ratio [OR] 4.5; 95\% confidence interval $[\mathrm{Cl}]=1.3$ to 15.8 ) resulted in an increased risk of admission. The most important independent risk factor was the presence of chronic obstructive pulmonary disease (COPD; OR 4.0; $95 \% \mathrm{Cl}=$ 1.4 to 11.4 ), other chronic disease (OR $2.9 ; 95 \% \mathrm{Cl}=1.2$ to 7.0 ), or both (OR $6.7 ; 95 \% \mathrm{Cl}=2.4$ to 18.4 ). Being housebound was also an independent risk factor (OR 2.2; $95 \% \mathrm{Cl}=1.0$ to 4.8 ).

\section{Conclusion}

Socioeconomic factors had little relative effect compared with medical and functional factors. The most important was the presence of long-term medical conditions (especially COPD), being housebound, and having received two or more courses of oral steroid treatment in the previous year. This combination of factors could be used by primary medical services to identify older patients most vulnerable to winter admissions. Clinicians should ensure that patients with COPD are better supported to manage their condition.

\section{Keywords}

elderly; hospitalisation; chronic obstructive pulmonary disease; respiratory tract infections; socioeconomic factors; winter pressures.

\section{INTRODUCTION}

Every winter, hospitals in many developed countries experience a surge in demand for emergency admissions, ${ }^{1-5}$ primarily from older patients with acute respiratory infections or chronic obstructive pulmonary disease (COPD). ${ }^{1,6}$ This incurs huge costs (over $£ 100$ million annually in the UK), ${ }^{6,7}$ but could potentially be avoided for some patients. In addition, for older people, there is an increased risk of contracting hospital-acquired infections while in hospital, and of reduced functioning after a hospital stay. ${ }^{8,9}$

To deliver appropriate interventions, knowledge of the factors that increase the risk of admission is

RE Jordan, $M P H, P h D$, British Lung Foundation research scientist; $\boldsymbol{P}$ Adab, MD, senior clinical lecturer; KK Cheng, PhD, MRCGP, professor of epidemiology, Department of Public Health and Epidemiology; RJ McManus, PhD, FRCGP, medical director; $R$ Salter, RGN, MMedSci, MidReC manager, MidReC, Department of Primary Care and General Practice, University of Birmingham; W Tunnicliffe, FRCP, consultant in respiratory and critical care medicine, Critical Care Unit, Selly Oak Hospital; B Olowukure, MBBS, PhD, regional epidemiologist, West Midlands Regional Surveillance Unit, Health Protection Agency, Birmingham. JI Hawker, FFPH, head of public health development, Health Protection Agency, London. JG Ayres, MD, FRCP, FRCPE, FFOM, professor of environmental and occupational medicine, Department of Environmental and Occupational Medicine, University of Aberdeen Liberty Safe Work Research Centre, Aberdeen. J Kai, MD, FRCGP, clinical professor of primary care, University of Nottingham Graduate Medical School, Derby City General Hospital, Derby.

Address for correspondence

Rachel E Jordan, Department of Public Health and Epidemiology, University of Birmingham, B15 2TT. E-mail: r.e.jordan@bham.ac.uk

Submitted: 25 June 2007; Editor's response: 9 August 2007; final acceptance: 26 March 2008.

(C)British Journal of General Practice.

This is the full-length article of an abridged version published in print. Cite this article as: Br J Gen Pract 2008; DOI: 10.3399/bjgp08X302682. 
required. Several ecological studies suggest that socioeconomic status may be an important determinant of respiratory admissions, ${ }^{10-12}$ but evidence at individual level is limited and conflicting. ${ }^{13-19}$ A large cohort study of 14223 adults in Copenhagen found that education and income were significant predictors of COPD admission, but unfortunately this study did not assess the impact of all important confounders. ${ }^{19}$ In a UK case-control study of pneumonia admissions among adults, deficient social support (being unemployed or unmarried) was a significant risk factor (adjusted odds ratio [OR] 1.5; 95\% confidence interval $[\mathrm{Cl}]=1.2$ to 1.9 ); whereas there was no significant effect of social class, type of heating, or crowding in the home. ${ }^{20}$

No study has yet quantified the independent effect of socioeconomic status and other measures of material deprivation, or the effect of social support on unplanned winter respiratory admissions among older people in the UK. Such data would inform intervention development, particularly whether and how health and social care could be better integrated.

This paper presents findings from a large case-control study in central England of older people presenting with acute respiratory disease. The aim was to identify which were the most important factors affecting the risk of hospitalisation and, in particular, to quantify the relative importance of social factors (socioeconomic, home environment, and social support), compared with medical and behavioural factors, such as smoking.

\section{METHOD}

\section{Study design}

A case-control study was conducted during winter 2003-2004, nested within a cohort of older people

\section{How this fits in}

Annual winter pressures in UK hospitals are largely the result of emergency respiratory admissions among the older population; however, it is not clear which are the most important risk factors, and especially the relative contribution of social and socioeconomic factors. In this case-control study, a set of key risk factors were identified that could allow identification by GPs of those most at risk of admission. Socioeconomic factors had little effect compared with factors relating to long-term medical conditions, although there was an increased risk in those who had no regular contact with family or friends. Having chronic obstructive pulmonary disease was the single most important risk factor and clinicians should focus on better management of these patients.

registered with 79 participating practices in central England, in conjunction with the Midlands Research Consortium of General Practices (MidReC) and Trent Focus research networks.

\section{Patients included in the cohort}

Patients were included if they were aged 65-89 years, registered with participating practices, and consulted their GP (or other emergency medical services such as accident and emergency [A\&E] and out-of hours services) with acute respiratory disease (defined as an acute episode of respiratory infection or acute exacerbation of preexisting respiratory disease) between 1 October 2003 and 31 March 2004 (Figure 1). Patients with simple upper respiratory tract infections were excluded. Identification of patients admitted to hospital using general practice records alone was found to be incomplete. To reduce selection bias, eligible cases were also identified using data from six large local hospitals and traced back to the participating GP.
Figure 1. Patients included in the study cohort.

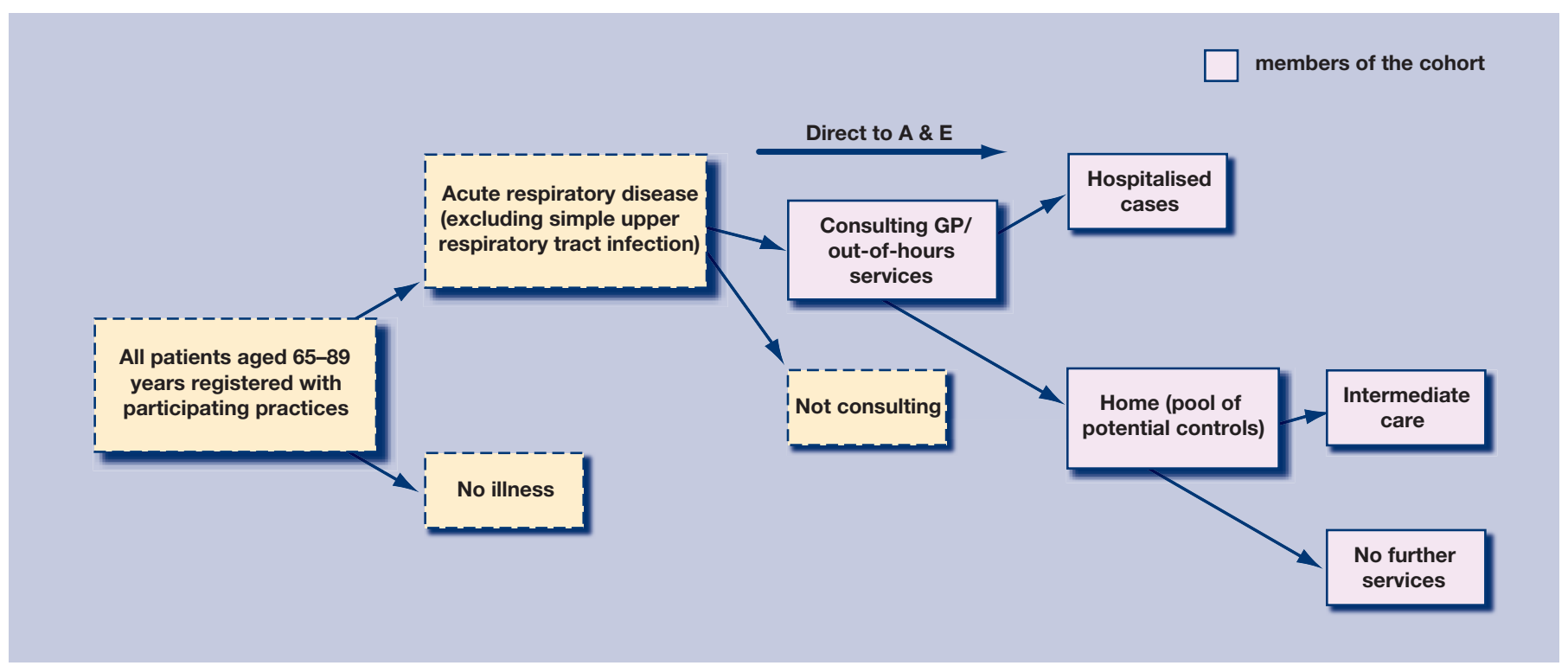




\section{Selection of cases and controls}

From the included cohort of patients outlined above, cases were defined as all patients admitted to hospital with acute respiratory disease (excluding upper respiratory tract infection). Only first admissions during the study period were included. Surviving cases were invited for interview.

Controls were also taken from the above cohort of patients, but were those managed in the community. Six controls were selected per case to mitigate for a potential low uptake, with the aim of achieving four controls interviewed per case. Controls were matched to cases for age (within \pm 5 years where possible), sex, and consultation date (within \pm 7 days where possible). Only first consultations for new episodes were included.

Patients who were deemed by their GP to be unable to consent to interview (for example, if they had dementia or other cognitive impairment) were not invited. Each selected patient was sent a standard invitation letter from their GP, a minimum of 2 weeks after their illness to allow time for recovery. A reminder was issued after 2-4 weeks. Cases and controls were interviewed within \pm 2 weeks of each other where possible.

\section{Data collection}

A trained nurse interviewed all participants at their homes (where informed consent was given) using a standard questionnaire that had been developed and piloted on a similar population. Validated questions were used about general health, smoking status, accommodation, home ownership, home heating, ${ }^{21}$ self-reported damp, ${ }^{22}$ ownership of household items, social support, ${ }^{21}$ ethnicity, ${ }^{23}$ and country of birth. Patients' functional scores were also derived, ${ }^{24}$ and data were obtained from patients about their demographic characteristics, economic status, health service use, and use of medications.

Information on age, sex, symptoms, and clinical diagnosis was obtained from the general practice records for all patients. Further details about postcode, diagnosed medical conditions, and previous health service use were obtained for all invited participants. Where possible, GPs also provided information on smoking status, ethnicity, functional status, and whether the patient lived alone, to assess potential differences between responders and non-responders (these data were not used for the main analysis as their accuracy was not thought to be as good as patient reports). A deprivation category was assigned to patients' home postcodes using the Townsend score from the 2001 census, ${ }^{25}$ at the level of the output area. Rural/urban status was derived from the 2001 census of the ward of the general practice at which the patient was registered.

\section{Statistical analysis}

Univariate odds ratios were calculated using conditional logistic regression. Variables with statistically significant $(P<0.05)$ or potentially clinically important effects were introduced sequentially into a multivariate conditional logistic regression model according to predicted importance. Models were tested using the likelihood ratio test. All statistical tests were undertaken using STATA (version 8). A conservative estimate of the number of courses of oral steroids in the year before entry to the study was used (reported number minus 1) to account for possible inclusion of the index consultation in the report of oral steroid courses.

The study was designed to interview 150 cases and 450 controls to achieve $80 \%$ power to detect an odds ratio of 1.9 (and above) at the 5\% significance level for 'receipt of housing benefit' and 'having no central heating': proxies for lower socioeconomic status/poorer housing for which there was information available.

\section{RESULTS}

\section{Description of patient cohort}

There were 3970 eligible patients identified, with mean age of 76 years, and $55.9 \%$ were female. Five hundred (12.6\%) were admitted to hospital. These patients were significantly older (mean age 78.1 years) than patients who were not admitted (75.7 years) $(P<0.001)$, and more likely to be male (relative risk 1.2; $95 \% \mathrm{Cl}=1.0$ to 1.4 ).

Recruitment rates for the case-control study Figure 2 illustrates the flow of recruitment for the case-control study. Among 393 cases and 2154 controls invited, 174 (44.3\%) and 1174 (54.5\%) respectively, agreed to be interviewed. No response was received from $42.5 \%$ of the cases of whom about half had either died, moved away, or were judged unsuitable for interview by their GP. Finally, 157 (39.9\%) cases and 639 (29.7\%) controls were interviewed, and 137 matched groups with a complete set of data were included in the final analysis.

\section{Effect of demographic, social, medical, and other factors on risk of winter hospital admission}

The relationship between each factor and hospital admission is summarised in Table 1.

Cases were more likely than controls to be current smokers (OR 3.2; $95 \% \mathrm{Cl}=1.8$ to 5.8 ), and patients of white Irish ethnic origin were significantly more likely to be admitted to hospital. At area level, there was a trend towards an increased risk of admission in more deprived areas. Cases were also less likely to 
be from rural areas and more likely to live in poorlyheated houses (although the latter was of borderline significance). More cases than controls were in receipt of income support and fewer cases owned their home, although neither of these factors had statistically significant effects. In terms of social support, cases were significantly less likely to see family or friends regularly.

Among medical factors, having COPD was significantly associated with admission (OR 3.2; $95 \% \mathrm{Cl}=2.2$ to 4.9$)$. Patients who reported poor general health $(\mathrm{OR}$ not good health $3.4 ; 95 \% \mathrm{Cl}=$ 2.0 to 5.7 ), or were housebound (OR $4.0 ; 95 \% \mathrm{Cl}=$ 2.3 to 7.2 ) had higher risk of admission. Cases were more likely to have been hospitalised in the previous year for a medical condition (OR 7.4; 95\% $\mathrm{Cl}=2.7$ to 20.1 ) and to have seen their GP more than once per month. They were also significantly more likely to have received courses of oral steroids in the previous year.

\section{Risk factors for winter admission from adjusted multivariate models}

Table 2 shows the risk factors for winter hospital admission from the final multivariate model. The most important single independent risk factor for admission was having COPD (OR 4.0; 95\% Cl = 1.4 to 11.4), and patients who had both COPD and another chronic disease had the highest risk (OR 6.7; $95 \% \mathrm{Cl}=2.4$ to 18.4). Patients hospitalised twice or more in the previous year for medical reasons had an independent risk of admission (OR 4.6; $95 \% \mathrm{Cl}=1.3$ to 16.0). Patients who were housebound had a higher risk (OR 2.2; $95 \% \mathrm{Cl}=1.0$ to 4.8 ), as did those who had received at least two courses of oral steroids in the previous year $(\mathrm{OR} 2.4 ; 95 \% \mathrm{Cl}=1.3$ to 4.6$)$. Patients who lived in rural areas were at lower risk of admission (OR $0.5 ; 95 \% \mathrm{Cl}=0.3$ to 0.8 ).

The effect of area-level deprivation observed in the univariate analysis disappeared after adjustment for the factors above. Inclusion of measures of individual deprivation, housing, and poor heating had little effect (data not shown). However, among patients with no regular contact with family or friends, the risk of admission was greater (OR 4.5; $95 \% \mathrm{Cl}=1.3$ to 15.8 ).

\section{Assessment of selection bias}

Table 2 also shows the effect of restricting the analysis to patients identified directly from the GPs

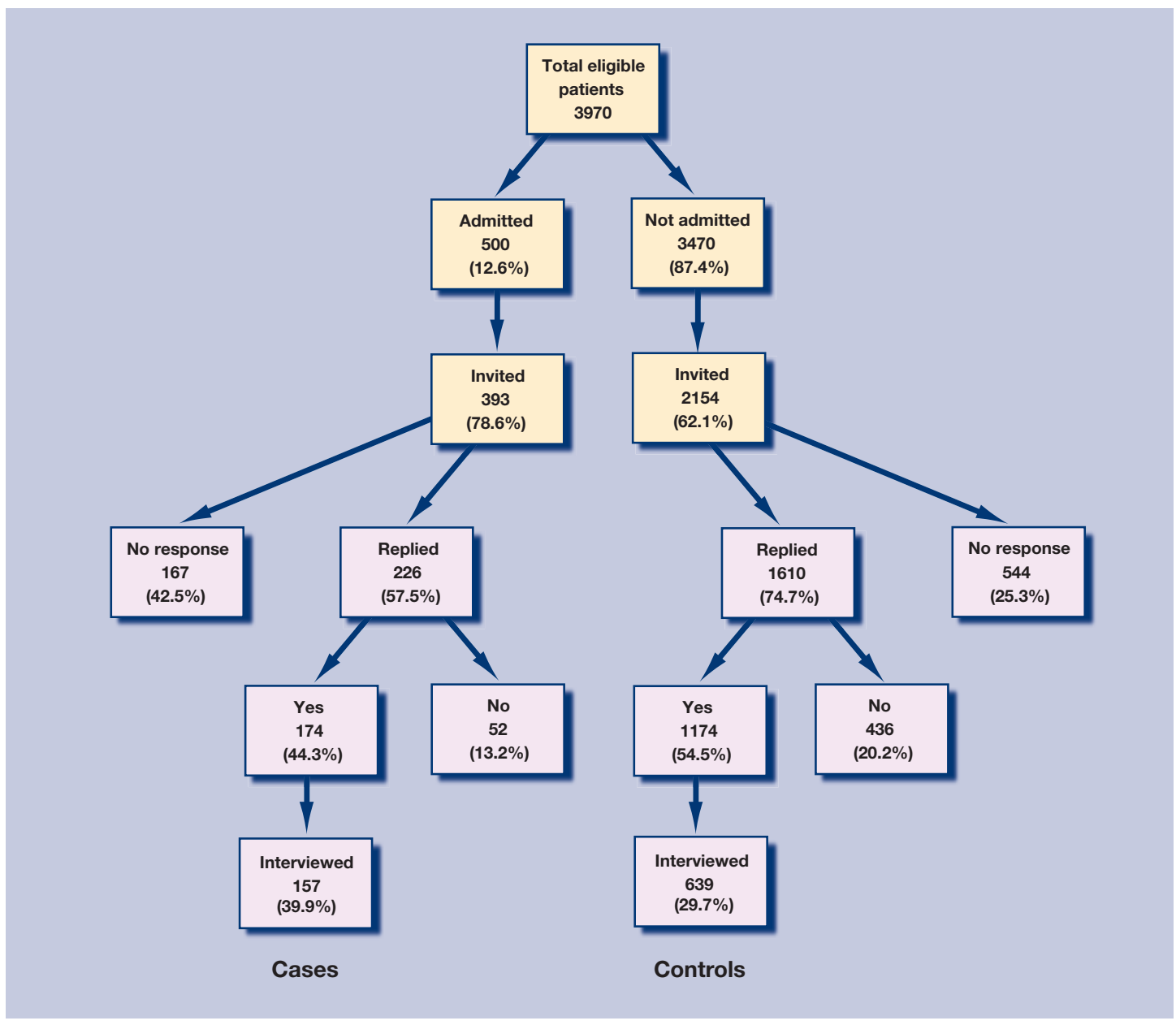

Figure 2. Flow chart of recruitment for case-control study. 


\begin{tabular}{|c|c|c|c|c|}
\hline \multirow[b]{2}{*}{ Factor } & \multicolumn{2}{|c|}{$n(\%)$} & \multirow[b]{2}{*}{$\begin{array}{c}\text { OR } \\
(95 \% \mathrm{Cl})^{\mathrm{a}}\end{array}$} & \multirow[b]{2}{*}{$P$-value } \\
\hline & $\begin{array}{c}\text { Cases } \\
(n=157)\end{array}$ & $\begin{array}{l}\text { Controls } \\
(n=639)\end{array}$ & & \\
\hline \multicolumn{5}{|l|}{ Demographic factors } \\
\hline Mean age, years & 77.0 & 76.5 & & \\
\hline \multicolumn{5}{|l|}{ Sex } \\
\hline Female & $70(44.6)$ & $291(45.5)$ & & \\
\hline Male & $87(55.4)$ & $348(54.5)$ & & \\
\hline \multicolumn{5}{|l|}{ Ethnicity } \\
\hline White British & $137(87.3)$ & $603(94.4)$ & 1.0 & \\
\hline White Irish & $12(7.6)$ & $17(2.7)$ & 3.6 (1.6 to 8.1$)$ & 0.002 \\
\hline Other & $8(5.1)$ & $19(3.0)$ & 2.5 (1.0 to 6.4$)$ & 0.060 \\
\hline \multicolumn{5}{|l|}{ Social and socioeconomic factors } \\
\hline \multicolumn{5}{|l|}{ Townsend quintile (patient postcode) } \\
\hline 1 (least deprived) & $26(17.1)$ & $126(20.7)$ & 1.0 & \\
\hline 2 & $24(15.8)$ & $128(21.0)$ & $1.1(0.6$ to 1.9$)$ & 0.900 \\
\hline 3 & $30(19.7)$ & $122(20.0)$ & $0.9(0.5$ to 1.7$)$ & 0.800 \\
\hline 4 & $34(22.4)$ & $119(19.5)$ & $1.6(0.9$ to 2.8$)$ & 0.100 \\
\hline 5 (most deprived) & $38(25.0)$ & $115(18.9)$ & $1.7(0.9$ to 3.0$)$ & 0.080 \\
\hline \multicolumn{5}{|l|}{ Rural urban index } \\
\hline Urban & $123(78.3)$ & $417(65.2)$ & 1.0 & \\
\hline Rural & $34(21.7)$ & $222(34.7)$ & $0.5(0.3$ to 0.8$)$ & 0.001 \\
\hline \multicolumn{5}{|l|}{ Home heating status } \\
\hline Fully heated & $134(85.4)$ & $581(90.9)$ & 1.0 & \\
\hline Part heated & $22(14.0)$ & $57(8.9)$ & $1.5(0.9$ to 2.1$)$ & 0.130 \\
\hline Not heated & $1.0(0.64)$ & 0 & & \\
\hline \multicolumn{5}{|l|}{ Receiving income support } \\
\hline No & $113(72.0)$ & $497(77.8)$ & 1.0 & \\
\hline Yes & $44(28.0)$ & $142(22.2)$ & $1.4(0.9$ to 2.1$)$ & 0.160 \\
\hline \multicolumn{5}{|l|}{ Owns home/mortgage } \\
\hline No & $64(40.8)$ & $220(34.4)$ & 1.0 & \\
\hline Yes & $93(59.2)$ & $419(65.6)$ & $0.8(0.6$ to 2.1$)$ & 0.260 \\
\hline \multicolumn{5}{|l|}{ Living alone } \\
\hline No & $103(65.6)$ & $422(66.0)$ & 1.0 & \\
\hline Yes & $54(34.4)$ & 217 (34.0) & $1.0(0.6$ to 1.2$)$ & 1.000 \\
\hline \multicolumn{5}{|l|}{ See family or friends regularly } \\
\hline Yes & $146(93.0)$ & $621(97.2)$ & 1.0 & \\
\hline No & $11(7.0)$ & $18(2.8)$ & $3.2(1.3$ to 7.7$)$ & 0.010 \\
\hline \multicolumn{5}{|l|}{ Medical and behavioural factors } \\
\hline \multicolumn{5}{|l|}{ Smoking status } \\
\hline Never smoker & $27(17.2)$ & $172(26.9)$ & 1.0 & \\
\hline Ex-smoker & $88(56.1)$ & $385(60.3)$ & 1.4 (0.9 to 2.3$)$ & 0.170 \\
\hline Current smoker ${ }^{b}$ & $42(26.8)$ & $82(12.8)$ & $3.2(1.8$ to 5.8$)$ & $<0.001$ \\
\hline \multicolumn{5}{|l|}{ Physician-diagnosed medical conditions } \\
\hline Chronic obstructive pulmonary disease & $77(49.0)$ & $153(23.9)$ & $3.2(2.2$ to 4.9$)$ & $<0.001$ \\
\hline Heart disease & $59(23.0)$ & $98(18.2)$ & $1.4(1.0$ to 2.1$)$ & 0.070 \\
\hline Asthma & $31(19.8)$ & $122(19.1)$ & $1.1(0.7$ to 1.7$)$ & 0.790 \\
\hline Diabetes & $21(13.4)$ & $83(13.0)$ & $1.1(0.7$ to 2.0$)$ & 0.610 \\
\hline Previous cancer & $8(20.0)$ & $149(19.7)$ & $1.0(0.5$ to 2.4$)$ & 0.900 \\
\hline Hospitalisation in previous year & & & & \\
\hline No & $122(77.7)$ & $577(90.3)$ & 1.0 & \\
\hline Once & $15(9.6)$ & $38(6.0)$ & $1.6(0.8$ to 3.1$)$ & 0.140 \\
\hline Twice or more & $11(7.0)$ & $8(1.3)$ & $7.4(2.7$ to 20.1$)$ & $<0.001$ \\
\hline Seen GP in the previous year & & & & \\
\hline Not at all & $1(0.6)$ & $3(0.5)$ & 10 & \\
\hline Once per year & $11(7.0)$ & $71(11.1)$ & \} 1.0 & \\
\hline Several times per year & $111(70.7)$ & 468 (73.2) & $1.4(0.7$ to 2.8$)$ & 0.300 \\
\hline Once or more per month & $34(21.7)$ & $95(14.9)$ & $2.2(1.1$ to 4.6$)$ & 0.040 \\
\hline
\end{tabular}




\begin{tabular}{|c|c|c|c|c|}
\hline \multirow[b]{2}{*}{ Factor } & \multicolumn{2}{|c|}{$n(\%)$} & \multirow[b]{2}{*}{$\begin{array}{c}\text { OR } \\
(95 \% \mathrm{Cl})^{\mathrm{a}}\end{array}$} & \multirow[b]{2}{*}{$P$-value } \\
\hline & $\begin{array}{c}\text { Cases } \\
(n=157)\end{array}$ & $\begin{array}{c}\text { Controls } \\
(n=639)\end{array}$ & & \\
\hline \multicolumn{5}{|c|}{ Physician-diagnosed medical conditions } \\
\hline \multicolumn{5}{|l|}{ Functional score } \\
\hline Independent & $74(47.1)$ & $437(68.4)$ & 1.0 & \\
\hline Restricted & $52(33.1)$ & $158(24.7)$ & 1.8 (1.2 to 2.7$)$ & 0.006 \\
\hline Housebound & $31(19.7)$ & $44(6.9)$ & 4.0 (2.3 to 7.2$)$ & $<0.001$ \\
\hline \multicolumn{5}{|l|}{ General health } \\
\hline Good & $24(15.3)$ & $187(29.3)$ & 1.0 & \\
\hline Fairly good & $56(35.7)$ & $292(45.7)$ & $1.5(0.9$ to 2.4$)$ & 0.12 \\
\hline Not good & $76(48.4)$ & $160(25.0)$ & 3.4 (2.0 to 5.7$)$ & $<0.001$ \\
\hline \multicolumn{5}{|l|}{ Oral steroids ${ }^{c}$} \\
\hline None & 94 (59.9) & $516(80.8)$ & 1.0 & \\
\hline 1 course & $17(10.8)$ & $36(5.6)$ & $2.6(1.3$ to 5.1$)$ & 0.006 \\
\hline 2 or more courses & 36 (22.9) & $64(10.0)$ & $2.9(1.8$ to 4.7$)$ & $<0.001$ \\
\hline
\end{tabular}

${ }^{\mathrm{a} C}$ Conditional analyses. ${ }^{\mathrm{b}}$ Includes smokers who quit less than 12 months previously. ${ }^{\mathrm{c}}$ Conservative estimate: reported number of courses minus 1 . OR = odds ratio.

(that is, excluding cases notified by the hospitals only). This resulted in a marked loss of power, although the effect estimates remained consistent with the full analysis. Having COPD and other conditions remained a strong risk factor, although the effect size was underestimated.

\section{Potential effect of non-response bias}

The effect of non-response on unadjusted risks of admission was assessed. For most variables, there was little difference in key risk factors between all invited patients (including non-responders) and finally interviewed patients. The effect of area-level deprivation may have been underestimated (OR for most deprived quintile $1.7 ; 95 \% \mathrm{Cl}=0.9$ to 3.0 for interviewed patients; for all invited patients including the non-responders, OR 2.3; $95 \% \mathrm{Cl}=1.6$ to 3.4). However, it is likely that once adjusted for other covariates, the effect, if any, would be small.

\section{DISCUSSION}

\section{Summary of main findings}

This is the first study to quantify adequately the relative effect of social factors, alongside medical and other factors, on the risk of acute winter respiratory admissions among older people in the UK. The study focused on people who consulted with lower respiratory tract infections or exacerbations, and, therefore, on the factors related to unplanned hospitalisation in this population. Socioeconomic factors, such as measures of material deprivation and poor housing, had little effect on risk of admission once adjusted for other significant factors, although socially isolated older people were more likely to be admitted. The key risk factor, given its high prevalence, was having COPD, and this risk was increased with additional comorbid conditions. Those patients who were housebound or who had several admissions in the previous year were additionally at risk, as were those who had received multiple courses of oral steroids.

\section{Strengths and limitations of the study}

The study had low uptake, partly because nearly one-third of the hospitalised patients died within 3 months of being admitted and therefore could not take part in the questionnaire. This resulted in reduced power for many of the outcome measures. However, assessment of non-response bias suggested no major effect on the results. For arealevel deprivation, once adjusted for other important confounders the effect is likely to have been small (in the multivariate analysis the effect of the fifth quintile of deprivation reduced the OR from 1.7 to 1.0). It is possible that all eligible admissions were not captured, as only six hospitals provided the researchers with relevant patient admissions, but the strategy used is likely to have reduced the effect of selection bias within the cases.

Although recall in older people could be a problem, the main variables in the questionnaire were simple closed-ended responses, with information such as smoking status and housing conditions which is likely to remain stable over time. Hospitalised patients should have been no more likely to have recall problems with these factors than those treated at home. Reduction of the number of oral steroid prescriptions by one allowed for courses given in response to the index illness.

Data were over $98 \%$ complete for most of the key variables, but there was some potential for 


\section{Table 2. Risk factors for winter respiratory hospital admissions from adjusted multivariate models.}

\begin{tabular}{|c|c|c|}
\hline & Final model ${ }^{b}$ & $\begin{array}{c}\text { Excluding admissions } \\
\text { identified by } \\
\text { hospital search only }\end{array}$ \\
\hline Risk factors ${ }^{a}$ & OR $(95 \% \mathrm{Cl})$ & OR $(95 \% \mathrm{Cl})$ \\
\hline Age, per year & 1.17 (1.05 to 1.31$)$ & 1.18 (1.03 to 1.35$)$ \\
\hline $\begin{array}{l}\text { Chronic conditions } \\
\text { None } \\
\text { COPD only } \\
\text { Other condition } \\
\text { COPD and other condition }\end{array}$ & $\begin{array}{c}1.0 \\
4.0(1.4 \text { to } 11.4) \\
2.9(1.2 \text { to } 7.0) \\
6.7(2.4 \text { to } 18.4) \\
\end{array}$ & $\begin{array}{c}1.0 \\
3.9(1.3 \text { to } 12.1) \\
2.6(1.0 \text { to } 6.8) \\
5.0(1.6 \text { to } 15.5) \\
\end{array}$ \\
\hline $\begin{array}{l}\text { Smoking status } \\
\text { Never smoker } \\
\text { Ex-smoker } \\
\text { Current smoker }^{d}\end{array}$ & $\begin{array}{c}1.0 \\
1.2(0.6 \text { to } 2.2) \\
1.8(0.8 \text { to } 4.0)\end{array}$ & $\begin{array}{c}1.0 \\
1.3(0.6 \text { to } 2.8) \\
3.2(1.2 \text { to } 8.7)\end{array}$ \\
\hline $\begin{array}{l}\text { Hospitalisation in previous year } \\
\text { No } \\
\text { Once } \\
\text { Twice or more }\end{array}$ & $\begin{array}{c}1.0 \\
1.0(0.4 \text { to } 2.5) \\
4.6(1.3 \text { to } 16.0)\end{array}$ & $\begin{array}{c}1.0 \\
1.9(0.6 \text { to } 5.6) \\
5.9(1.6 \text { to } 21.6)\end{array}$ \\
\hline $\begin{array}{l}\text { Functional score } \\
\text { Independent } \\
\text { Restricted } \\
\text { Housebound/chair/bed-bound }\end{array}$ & $\begin{array}{c}1.0 \\
1.0(0.5 \text { to } 1.7) \\
2.2(1.0 \text { to } 4.8)\end{array}$ & $\begin{array}{c}1.0 \\
1.0(0.5 \text { to } 1.9) \\
1.3(0.5 \text { to } 3.3)\end{array}$ \\
\hline $\begin{array}{l}\text { Ethnicity } \\
\text { White British } \\
\text { White Irish } \\
\text { Other }\end{array}$ & $\begin{array}{c}1.0 \\
4.3(1.3 \text { to } 14.3) \\
1.9(0.4 \text { to } 8.5)\end{array}$ & $\begin{array}{c}1.0 \\
2.9(0.6 \text { to } 12.8) \\
1.7(0.2 \text { to } 13.0)\end{array}$ \\
\hline $\begin{array}{l}\text { Rural urban index } \\
\text { Urban } \\
\text { Rural }\end{array}$ & $\begin{array}{c}1.0 \\
0.5(0.3 \text { to } 0.8)\end{array}$ & $\begin{array}{c}1.0 \\
0.7(0.4 \text { to } 1.3)\end{array}$ \\
\hline $\begin{array}{l}\text { Oral steroids } \\
\text { None } \\
1 \text { course } \\
2 \text { courses or more courses }\end{array}$ & $\begin{array}{c}1.0 \\
1.6(0.7 \text { to } 3.7) \\
2.4(1.3 \text { to } 4.6)\end{array}$ & $\begin{array}{c}1.0 \\
1.6(0.6 \text { to } 4.3) \\
3.3(1.5 \text { to } 7.0)\end{array}$ \\
\hline $\begin{array}{l}\text { Regular contact with friends or } f \\
\text { Yes } \\
\text { No }\end{array}$ & $\begin{array}{c}1.0 \\
4.5(1.3 \text { to } 15.8)\end{array}$ & $\begin{array}{c}1.0 \\
5.2(1.1 \text { to } 25.7)\end{array}$ \\
\hline
\end{tabular}

anly risk factors included in the final models are shown; all covariates adjusted for each other. 'Based on 575 observations. 'Based on 426 observations. I/ncludes smokers who quit less than 12 months previously. ${ }^{\circ}$ Conservative estimate: reported number of courses minus 1 (patient-reported). $C O P D=$ chronic obstructive pulmonary disease. $O R=$ odds ratio.

misclassification; data on hospitalisation rates may be underestimated in general practice records and there is known under-diagnosis and misdiagnosis of COPD in primary care. ${ }^{26}$ In addition, it is known to be difficult to capture socioeconomic status in older people, ${ }^{27}$ although measures were chosen that have been shown in previous studies to be associated with poor health. ${ }^{28}$ Functional score or general health may have changed in response to the illness.

\section{Comparison with existing literature}

In contrast to the suggestions from ecological studies, ${ }^{10-12}$ but in line with other individual-level studies, ${ }^{14-18}$ material deprivation was not observed to be an important independent risk factor for admission.
Several observational studies show that indoor temperature might be an important contributory factor in respiratory morbidity and mortality during winter, ${ }^{29-32}$ but there is no other individual-level study assessing its effect on respiratory admissions. The power in the final analysis of this study was not sufficient to test this appropriately; also the method for determining heating levels was crude.

Living alone had no effect on admission, but patients without regular visits from friends or family were shown to have higher risk. Only one other relevant study was identified that investigated the effect of deficient social support, showing a small increased risk (OR $1.5 ; 95 \% \mathrm{Cl}=1.2$ to 1.9 ) for adult pneumonia admissions to UK hospitals. ${ }^{20}$

While social factors had relatively little effect on increasing the risk of hospital admission, this study showed that medical and functional factors were very important. The most important independent risk factor (given the high prevalence) was the presence of COPD with another comorbidity; such patients had over six times the risk of admission compared with patients with no comorbidities. This is consistent with other studies showing independent risks of COPD and heart disease. ${ }^{14,15,18,20,21,33-35}$ Patients with multiple hospitalisations in the previous year also had significantly increased risk. This is concordant with two other small studies of COPD admissions, ${ }^{16,17}$ but not with the lack of effect seen in two case-control studies of pneumonia admissions. ${ }^{14,15}$

The study found that patients who were housebound had increased risks of admission after adjustment for other factors. Concordant with a cohort study of adult patients with asthma, ${ }^{36}$ this study also found an increased risk of admission in patients receiving two or more courses of oral steroids in the previous year. This measure may reflect more severe or more poorly controlled chronic respiratory disease. In the present study, patients belonging to rural practices were less likely to be admitted than those from urban practices, even after adjustment for socioeconomic status. Some of this effect may be related to distance from hospital. ${ }^{37}$

\section{Implications for clinical practice}

The effects of social factors on the risk of acute respiratory admission among older people in winter are relatively minor compared with the effects of medical factors, although low levels of social support have an important effect. This suggests that public health measures to reduce winter admissions should not be focused only on deprived individuals or areas. This is also consistent with evidence from an ecological study 
of excess winter mortality and emergency admission in older people. ${ }^{38}$

The most important factors are the presence of long-term medical conditions (especially COPD), being housebound, and having received multiple courses of oral steroids. The study has identified a clear set of risk factors, most of which could be applied at the level of a general practice (or primary care trust) to help identify patients at risk. All but one of the patients in this study had seen their GP in the last year, so they should be easy to access.

This study provides further evidence of the potential benefit to be gained by better supporting people with COPD to manage their condition optimally, ${ }^{39,40}$ and to ensure that those with poor mobility benefit from pulmonary rehabilitation.

Given the latest targets of reducing emergency admissions by $5 \%,{ }^{41}$ these results should be useful to the UK government and are likely also to be useful to other European and North American countries that experience surges in respiratory admissions during the winter.

\section{Funding body}

The main source of funding was a grant from the British Lung Foundation (P01/10). Additional support was provided by Boehringer Ingelheim, Pfizer, 3M, South Birmingham PCT, and the Department of Health (Support for Science)

\section{Ethical approval}

Ethical approval was obtained from the West Midlands Multicentre Research Ethics Committee (MREC/02/7/52). Research governance approval was obtained from participating primary care trusts and NHS hospital trusts

\section{Competing interests}

The authors have stated that there are none

\section{Acknowledgements}

We would like to thank the research study team for their outstanding contribution to the WARM Study, and without whom the study would not have been possible. We would also like to thank all of the research nurses, practice managers, GPs and patients for taking part in the study. In addition, we are very grateful to MidREC and Trent Focus (and the other research networks) for allowing us access to their research practices, and Boehringer Ingelheim, Pfizer, $3 \mathrm{M}$, South Birmingham PCT, and the Department of Health (Support for Science) via MidReC for supporting the study, and our main sponsors, the British Lung Foundation

\section{Discuss this article}

Contribute and read comments about this article on the Discussion Forum: http://www.rcgp.org.uk/bjgp-discuss

\section{REFERENCES}

1. Damiani M, Dixon J. Managing the pressure. Emergency hospital admissions in London, 1997-2001. London: King's Fund Bookshop, 2001.

2. Department of Health. Winter report 2005-2006. London: Department of Health, 2006 http://www.dh.gov.uk/assetRoot/04/13/22/25/04132225.pdf (accessed 1 Apr 2008).

3. Menec V, Roos N, MacWilliam L. Seasonal patterns of hospital use in Winnipeg: implications for managing winter bed crises. Healthc Manage Forum 2002; Suppl: 58-64.

4. Upshur R, Moineddin R, Crighton E, et al. Simplicity within complexity: seasonality and predictability of hospital admissions in the province of Ontario 1988-2001, a population-based analysis. BMC Health Serv Res 2005; 5(1): 13.
5. Saynajakangas P, Keistinen T, Tuuponen T. Seasonal fluctuations in hospitalisation for pneumonia in Finland. Int J Circumpolar Health 2001; 60(1): 34-40.

6. Department of Health. Hospital Episode Statistics. 1990-99. http://www.dh.gov.uk/en/Publicationsandstatistics/Statistics/Hos pitalEpisodeStatistics/index.htm (accessed 30 Apr 2008).

7. Department of Health. Reference costs 2005-06. London: Department of Health, 2006.

http://www.dh.gov.uk/en/Publicationsandstatistics/Publications/Pu blicationsPolicyAndGuidance/DH_062884 (accessed 30 Apr 2008).

8. El Solh A, Pineda L, Bouquin P, Mankowski C. Determinants of short and long term functional recovery after hospitalization for community-acquired pneumonia in the elderly: role of inflammatory markers. BMC Geriatr 2006; 6(12): 1-10.

9. Plowman R, Graves N, Griffin MAS, et al. The rate and cost of hospital-acquired infections occurring in patients admitted to selected specialties of a district general hospital in England and the national burden imposed. J Hosp Infect 2001; 47(3): 198-209.

10. Hawker JI, Olowokure B, Sufi F, et al. Social deprivation and hospital admission for respiratory infection: an ecological study. Respir Med 2003; 97(11): 1219-1224.

11. Watson JP, Cowen P, Lewis RA. The relationship between asthma admission rates, routes of admission, and socioeconomic deprivation. Eur Respir J 1996; 9(10): 2087-2093.

12. Gilthorpe MS, Lay-Yee R, Wilson RC, et al. Variations in hospitalization rates for asthma among black and minority ethnic communities. Respir Med 1998; 92(4): 642-648.

13. Crocetti E, Arniani S, Bordoni F, et al. Effectiveness of influenza vaccination in the elderly in a community in Italy. Eur $J$ Epidemiol 2001; 17(2): 163-168.

14. Puig-Barbera J, Diez-Domingo J, Perez HS, et al. Effectiveness of the MF59-adjuvanted influenza vaccine in preventing emergency admissions for pneumonia in the elderly over 64 years of age. Vaccine 2004; 23(3): 283-289.

15. Puig-Barbera J, Marquez-Calderon S, Masoliver-Fores A, et al. Reduction in hospital admissions for pneumonia in noninstitutionalised elderly people as a result of influenza vaccination: a case-control study in Spain. J Epidemiol Community Health 1997; 51(5): 526-530.

16. Garcia-Aymerich J, Farrero E, Felez MA, et al. Risk factors of readmission to hospital for a COPD exacerbation: a prospective study. Thorax 2003; 58(2): 100-105.

17. Garcia-Aymerich J, Monso E, Marrades RM, et al. Risk factors for hospitalization for a chronic obstructive pulmonary disease exacerbation. EFRAM study. Am J Respir Crit Care Med 2001; 164(6): 1002-1007.

18. O'Meara ES, White M, Siscovick DS, et al. Hospitalization for pneumonia in the Cardiovascular Health Study: incidence, mortality, and influence on longer-term survival. J Am Geriatr Soc 2005; 53(7): 1108-1116.

19. Prescott E, Lange P, Vestbo J. Socioeconomic status, lung function and admission to hospital for COPD: results from the Copenhagen City Heart Study. Eur Respir J 1999; 13(5): 1109-1114.

20. Farr BM, Bartlett CL, Wadsworth J, Miller DL. Risk factors for community-acquired pneumonia diagnosed upon hospital admission. British Thoracic Society Pneumonia Study Group. Respir Med 2000; 94(10): 954-963.

21. Office for National Statistics SSD. Living in Britain. Results from the 1998 General Household Survey. London: The Stationery Office, 2000.

http://www.statistics.gov.uk/downloads/theme compendia/GHS9 8.pdf (accessed 1 Apr 2008).

22. Joint Health Surveys Unit of Social and Community Planning Research (SCPR) and the Department of Epidemiology and Public Health UCL. Health survey for England 1996. London: The Stationery Office, 1998.

23. Office for National Statistics. Census 2001. Ethnicity and religion in England and Wales. http://www.statistics.gov.uk/census2001/profiles/commentaries/et hnicity.asp (accessed 30 Apr 2008).

24. Menzies R, Gibbons W, Goldberg P. Determinants of weaning and survival among patients with COPD who require mechanical ventilation for acute respiratory failure. Chest 1989; 95(2): $398-405$. 
25. Townsend P, Phillimore P, Beattie A. Health and deprivation: inequality in the north. London: Routledge, 1988.

26. Shahab L, Jarvis MJ, Britton J, West R. Prevalence, diagnosis and relation to tobacco dependence of chronic obstructive pulmonary disease in a nationally representative population sample. Thorax 2006; 61(12): 1043-1047.

27. Grundy E, Holt G. The socioeconomic status of older adults: how should we measure it in studies of health inequalities? $J$ Epidemiol Community Health 2001; 55(12): 895-904.

28. Grundy E, Sloggett A. Health inequalities in the older population: the role of personal capital, social resources and socio-economic circumstances. Soc Sci Med 2003; 56(5): 935-947.

29. Rudge J, Gilchrist R. Excess winter morbidity among older people at risk of cold homes: a population-based study in a London borough. J Public Health 2005; 27(4): 353-358.

30. Evans J, Hyndman S, Stewart-Brown S, et al. An epidemiological study of the relative importance of damp housing in relation to adult health. J Epidemiol Community Health 2000; 54(9): 677-686.

31. Blane D, Mitchell R, Bartley M. The 'inverse housing law' and respiratory health. J Epidemiol Community Health 2000; 54(10): $745-749$.

32. Donaldson GC, Seemungal T, Jeffries DJ, Wedzicha JA. Effect of temperature on lung function and symptoms in chronic obstructive pulmonary disease. Eur Respir J 1999; 13(4): 844-849.

33. Foster DA, Talsma A, Furumoto-Dawson A, et al. Influenza vaccine effectiveness in preventing hospitalization for pneumonia in the elderly. Am J Epidemiol 1992; 136(3): 296-307.

34. Ohmit SE, Monto AS. Influenza vaccine effectiveness in preventing hospitalization among the elderly during influenza type A and type B seasons. Int J Epidemiol 1995; 24(6): $1240-1248$.

35. LaCroix AZ, Lipson S, Miles TP, White L. Prospective study of pneumonia hospitalizations and mortality of U.S. older people: the role of chronic conditions, health behaviors, and nutritional status. Public Health Rep 1989; 104(4): 350-360.

36. Schatz M, Cook EF, Joshua A, Petitti D. Risk factors for asthm hospitalizations in a managed care organization: development of a clinical prediction rule. Am J Manag Care 2003; 9(8): 538-547.

37. Haynes RM, Bentham CG. The effects of accessibility on general practitioner consultations, out-patient attendances and in patient admissions in Norfolk, England. Soc Sci Med 1982; 16(5): 561-569.

38. Maheswaran R, Chan D, Fryers PT, et al. Socio-economic deprivation and excess winter mortality and emergency hospital admissions in the South Yorkshire Coalfields Health Action Zone, UK. Public Health 2004; 118(3): 167-176.

39. The Department of Health. Supporting people with long term conditions, an NHS and social care model to support local innovation and integration. London: Department of Health, 2005

40. The National Collaborating Centre for Chronic Conditions. Chronic obstructive pulmonary disease. National clinical guideline on management of chronic obstructive pulmonary disease in adults in primary and secondary care. Thorax 2004; 59(Suppl 1): 1-232.

41. Department of Health. The NHS improvement plan. Putting people at the heart of public services. London: Department of Health, 2004.

http://www.dh.gov.uk/en/Publicationsandstatistics/Publications/ PublicationsPolicyAndGuidance/DH_4084476 (accessed 22 Apr 2008). 